\title{
The Moon as a Recorder of Organic Evolution in the Early Solar System: A Lunar Regolith Analog Study
}

\author{
Richard Matthewman, Richard W. Court, Ian A. Crawford, ${ }^{2}$ \\ Adrian P. Jones, ${ }^{3}$ Katherine H. Joy, ${ }^{4}$ and Mark A. Sephton ${ }^{1}$
}

\begin{abstract}
The organic record of Earth older than $\sim 3.8 \mathrm{Ga}$ has been effectively erased. Some insight is provided to us by meteorites as well as remote and direct observations of asteroids and comets left over from the formation of the Solar System. These primitive objects provide a record of early chemical evolution and a sample of material that has been delivered to Earth's surface throughout the past 4.5 billion years. Yet an effective chronicle of organic evolution on all Solar System objects, including that on planetary surfaces, is more difficult to find. Fortunately, early Earth would not have been the only recipient of organic matter-containing objects in the early Solar System. For example, a recently proposed model suggests the possibility that volatiles, including organic material, remain archived in buried paleoregolith deposits intercalated with lava flows on the Moon. Where asteroids and comets allow the study of processes before planet formation, the lunar record could extend that chronicle to early biological evolution on the planets. In this study, we use selected free and polymeric organic materials to assess the hypothesis that organic matter can survive the effects of heating in the lunar regolith by overlying lava flows. Results indicate that the presence of lunar regolith simulant appears to promote polymerization and, therefore, preservation of organic matter. Once polymerized, the mineral-hosted newly formed organic network is relatively protected from further thermal degradation. Our findings reveal the thermal conditions under which preservation of organic matter on the Moon is viable. Key Words: MoonRegolith-Organic preservation-Biomarkers. Astrobiology 15, 154-168.
\end{abstract}

\section{Introduction}

\subsection{Organic records in the Solar System}

T He PROCESSES THAT DRIVE Earth's geological cycle continually overwrite the rock record with new geological information. Tectonic activity has destroyed rocks older than $\sim 3.8 \mathrm{Ga}$, and the oldest rocks that we are able to examine have been heavily altered, complicating the interpretation of ancient terrestrial environments (e.g., Mojzsis et al., 1996; Fedo and Whitehouse, 2002; Lepland et al., 2005; van Kranendonk et al., 2007). We are, therefore, forced to look elsewhere for clues about the conditions on Earth and in the inner Solar System at and before $\sim 3.8 \mathrm{Ga}$. Meteorites have provided us with a great deal of information about the formation of the Solar System. However, what is needed is a record, over time, of the materials that were circulating close to, and impacting on, Earth during early phases of ocean, atmosphere, and continent formation and destruction (e.g., Marchi et al., 2014). Such materials would have derived from primitive and processed asteroids, comets, interplanetary dust particles, as well as fragments of planetary surfaces ejected by large impacts. Many of these bodies are known to contain organic material. In particular, the analysis of carbonaceous chondrite meteorites has revealed the wide variety of organic compounds that were generated abiotically and were available for delivery to planetary surfaces (Sephton, 2002). Some of these compounds, such as amino acids, carboxylic acids, polyhydroxylated compounds and nucleobases, have relevance to biological systems. Certain compounds appear to have a clear relationship with inorganic

\footnotetext{
${ }^{1}$ Impacts and Astromaterials Research Centre, Department of Earth Science and Engineering, South Kensington Campus, Imperial College London, London, UK.

${ }^{2}$ Department of Earth and Planetary Sciences, Birkbeck College, University of London, London, UK.

${ }^{3}$ Department of Earth Sciences, University College London, London, UK.

${ }^{4}$ School of Earth, Atmospheric and Environmental Sciences, University of Manchester, Manchester, UK.
} 
mineral phases (Pearson et al., 2002; Garvie and Buseck, 2007; Kebukawa et al., 2010; Zega et al., 2010; Le Guillou et al., 2014). Similarly, direct sampling by spacecraft and remote observations of comets and asteroidal bodies have revealed a range of organic compounds (Kissel and Krueger, 1987; Ehrenfreund and Charnley, 2000; Sandford et al., 2006; Elsila et al., 2009). These objects and the organic matter they carry are important in helping to understand prebiotic chemical evolution in the early Solar System. Yet a record of the subsequent emergence and evolution of the first biological systems on planetary surfaces is currently unavailable on Earth. However, the cratering record of the Moon and models of Solar System dynamics indicate an intense period of asteroid bombardment of the inner Solar System, around 4.2-3.7 Ga, known as the Late Heavy Bombardment (Hartmann et al., 2000; Kring and Cohen, 2002; Gomes et al., 2005; Tsiganis et al., 2005; Bottke et al., 2012; Marchi et al., 2012). Such impacts may have ejected fragments of terrestrial crust containing evidence of ancient rock types, trapped records of atmospheric gases, and potentially biomarkers (Armstrong et al., 2002). Capture and preservation of ejected planetary material could answer outstanding questions over the chemical evolution in the inner Solar System that led up to the origin of life.

The Moon may provide us with this archive (Armstrong et al., 2002; Crawford et al., 2008; Joy et al., 2012; Burchell et al., 2014b). Major surface volcanic activity on the Moon ceased around 3.1 Ga (Wilhelms et al., 1987). The Moon has essentially no atmosphere and is largely anhydrous. It is also a relatively large body $(3475 \mathrm{~km}$ diameter), causing it to readily attract material owing to its gravitational pull. These features make it a potentially ideal witness to the organic chemical processes occurring close to Earth in the early Solar System. The surface of the Moon is largely covered by a few meters to kilometers thickness of regolith, a fine-grained rock powder developed by impacting material and space weathering (Lucey et al., 2006). After the return of the Apollo lunar samples, a number of studies assessed the lunar materials for the presence of organic matter (e.g., Abell et al., 1970; Burlingame et al., 1970; Nagy et al., 1970). Small quantities of carbon were detected $(<200 \mathrm{ppm}$ total C, Burlingame et al., 1970; Ponnamperuma et al., 1970). The indigenous nature of detected organic compounds was uncertain. Measurements by Brinton and Bada (1996) quantified the level of free amino acids at around $15 \mathrm{ppb}$; however, some of the detected compounds were attributed to terrestrial contamination based on enantiomeric ratios. More recent studies in which highly sensitive modern instruments were used have indicated the presence of organic compounds in lunar samples that are not of terrestrial contamination origin but may have come from added meteoritic material (Thomas-Keprta et al., 2014). A lunar impact melt breccia returned from the Moon by Apollo 17 (sample 72255) has been shown to contain graphitic carbon that may have formed from condensation of vaporized C-rich impactors (Steele et al., 2010). Understanding how these carbonaceous materials were formed, and modified, would allow us to test proposed models of preservation. The presence of well-preserved records on the Moon may be crucial in illuminating the behavior and chemical evolution of organic matter in the early Solar System.

\subsection{Sources of organic matter to the Moon}

Organic matter is prevalent throughout the Solar System, and the possibility of the presence of indigenous organic matter on the Moon has been considered for some time (e.g., Sagan, 1960). In addition to exogenous delivery, organic compounds may be generated in situ by the action of radiation on ices (e.g., Moore et al., 1983; Bernstein et al., 1995; Lucey, 2000; Crites et al., 2013). Carbon may also be directly implanted in the regolith from the solar wind (Bibring et al., 1974; Pillinger and Eglinton 1977; Haskin and Warren, 1991). There would have been a number of sources that could have delivered organic and volatile material during the early history of the Earth-Moon system. Models have shown that enstatite and ordinary chondrite-type bodies would have been the dominant large impactor types during the Late Heavy Bombardment (Bottke et al., 2012; Morbidelli et al., 2012). These meteorite types are known to contain organic material (e.g., Alexander et al., 1998; Quirico et al., 2003; Sephton et al., 2004a). There would also have been a high flux of micrometeorites and dust particles at this time, dominated by carbonaceous material (Court and Sephton, 2014). CI carbonaceous chondrites can contain $>3 \%$ carbon (Botta and Bada, 2002), and interplanetary dust particles can contain several times this amount (Thomas et al., 1994). Another potential source of organic matter would have been from the surfaces of Mars, Earth, and other planets, as large impacts would have ejected fragments of surface material into space at velocities sufficient to escape the gravitational pull of the planets (Armstrong et al., 2002; Armstrong, 2010). Ejected fragments of planetary surfaces could potentially have contained organic matter, including biological material. The potential for preservation of the earliest biotic and prebiotic material in terrestrial or martian meteorites is a key motivation for exploration of the Moon (Crawford et al., 2008; Burchell et al., 2014b). Recent experimental work has shown the ability of organic biomarkers to survive the impact shock conditions that would have ejected this material from the planetary surface (e.g., Parnell et al., 2010; Burchell et al., 2014a). The total amount of terrestrial material at the lunar surface today has been estimated as 1-2 ppm; however, the distribution of impacts will be non-uniform, and some areas of the surface may have received several times more or less than this amount (Armstrong, 2010). The proportion of organic matter in the ejected terrestrial material is unknown; however, assuming organic-poor rocks with $1 \%$ organic matter or less would result in parts-per-billion levels of terrestrial organic matter in the lunar regolith.

\subsection{Survival of infalling material}

1.3.1. Impact at the lunar surface. Organic material within an ejected object traveling toward the lunar surface must survive the initial impact in order to be preserved. With a negligible atmosphere to provide deceleration, impacting bodies strike the lunar surface at high velocity, producing high temperatures and great levels of shock. The lack of atmosphere means that a fusion crust will not be developed on the meteorite by ablation; however, it has been suggested that material ejected from the surface of Earth may develop a fusion crust on its passage out of the atmosphere (Gutiérrez, 2002). The high temperatures generated 
during atmospheric ablation of stony meteorites falling to Earth are restricted to the outermost portion of the meteorite and do not penetrate to significant depth. The detection of organic compounds in carbonaceous chondrite meteorites and experimental work with artificial meteorites have shown that organic compounds and biomarkers are capable of surviving infall to Earth (Sears, 1975; Parnell et al., 2011). It might therefore be expected that organic compounds would survive heating by ablation in materials ejected from Earth's surface.

Micrometeorites impacting the lunar surface are vaporized, and the vapor subsequently condenses onto grain surfaces (Keller and McKay, 1997). The high impact temperatures generate glass-bound agglutinates that are abundant in the lunar regolith (e.g., McKay et al., 1991). However, a fraction of impacting material can survive. Direct evidence for survival following impact comes from a small number of meteorites recovered from regolith samples collected during the Apollo missions (e.g., Joy et al., 2012 and references therein). One important example is the Bench Crater meteorite, recovered by Apollo 12. This millimetersized object was identified as a carbonaceous chondrite, and the hydrated mineral phases remain preserved (McSween, 1976; Zolensky et al., 1996; Zolensky, 1997). Bench Crater provides encouragement that carbonaceous materials in meteorites may be identifiable and characterizable in situ on the Moon (see also Joy et al., 2012). Terrestrial meteorites would have had a lower range of impact velocities than asteroidal or cometary fragments. Armstrong (2010) calculated terrestrial meteorite impact velocities as typically occurring at $\sim 3 \mathrm{~km} \mathrm{~s}^{-1}$, with a substantial proportion of impactors having relatively low vertical impact velocities. Computer modeling has shown that portions of larger impactors $\left(0.125 \mathrm{~m}^{3}\right)$ experience relatively moderate conditions upon impact within the range of $2.5-5 \mathrm{~km} \mathrm{~s}^{-1}$, well within the survivability window for many biomarkers (Crawford et al., 2008; Burchell et al., 2010).

1.3.2. The lunar regolith environment. Despite the absence of tectonics, biodegradation, and other destructive agents that are present on Earth, the lack of an atmosphere on the Moon means that its surface is subjected to space weathering (e.g., Lucey et al., 2006). Space weathering constitutes impacts from micrometeorites and larger impactors (comminution) and irradiation from the solar wind, energetic solar events, and galactic cosmic rays. The radiation causes sputtering on grain surfaces, and the more energetic particles can generate a cascade of particles within the regolith, which alters the mineral grains. It has been shown that ionizing radiation can change the structure of organic matter by formation of free radicals during radiolysis, causing aromatization, a reduction in the degree of alkylation of aromatic units, and polymerization of smaller organic molecules into larger aromatic networks (Court et al., 2006). For fragile materials to be preserved over billion-year timescales, some mechanism is required to protect them from the harsh radiation and impact environment; processes related to lunar lava flows may provide one such mechanism.

\subsection{Preservation of the lunar regolith}

The continual process of lunar regolith formation is slow (2-5 mm $\mathrm{Myr}^{-1}$ over the last 3.5 billion years; e.g., McKay et al., 1991) and subjects materials to repeated vertical and lateral reworking and direct surface exposure. Given the current rate of overturn, it would take a considerable length of time to build up a thickness of regolith sufficient to completely protect material from ionizing radiation and impacts. Therefore, a more rapid mechanism of burial is required. Burial under an ejecta blanket or an impact melt flow from a nearby large impact is one possible method, but identification of discrete regolith horizons within the layers of pulverized rock and mixed regolith material would be a challenging task. A recently proposed alternative method of rapid burial is by lava flows (Crawford et al., 2010; Fagents et al., 2010; Rumpf et al., 2013). In the lava flow model, a layer of regolith that has accumulated on an exposed rock surface is covered by lava, which quickly cools. Subsequent space weathering develops a new regolith layer on the lava surface, which in turn is covered by another flow. Repeated again, this would result in a succession of paleoregolith deposits separated and protected from the space environment by layers of igneous rock. Analogous processes occur on Earth, with the development of soils on lava flows that are in turn buried by later flows, causing thermal alteration of soil material (e.g., Olson and Nettleton, 1998; Sheldon, 2003; Marques et al., 2014). The heating profiles below terrestrial lava flows have been modeled (e.g., Fagents and Greeley, 2001; Kerr, 2001), and there is an existing literature on the analysis of thermal metamorphism of organic matter-containing rocks as a result of igneous activity (e.g., Bishop and Abbott 1993, 1995; Farrimond et al., 1996). However, terrestrial conditions differ markedly from those on the Moon, particularly with the absence of water in the lunar rock profile. The sequence of lunar regolith and lava flow layers would record changes in the types of meteorite infall over time, as well as changes in other parameters of interest such as the radiation environment and particle fluxes (Crawford et al., 2010; Fagents et al., 2010; Joy et al., 2014). Combined with radiometric dating of the lava units, a sequence of lava-encapsulated regolith layers could provide a tightly defined record of processes occurring at the lunar surface including the receipt of material from elsewhere in the Solar System such as Earth's surface.

\subsection{The influence of volcanic heat on organic records}

Having established a possible method of preserving regolith deposits by lava flows, consideration needs to be made of the effects of heating of the materials of interest within the buried regolith by the lava. Heating of organic materials can result in the loss of volatile compounds, degradation, and aromatization (e.g., Killops and Killops, 2005). The presence of minerals is known to affect the alteration of organic matter during heating (e.g., Espitalié et al., 1980, 1984; Huizinga et al., 1987). Space weathering would gradually break up an organic-bearing meteorite on the surface of the regolith, with the result that a portion of the organic material would become dispersed within the lunar regolith, with direct contact between organic material and lunar minerals. The minerals of the lunar regolith may have properties that accelerate the destruction or reconfiguration of organic materials when heated, or otherwise result in organic products different to those where the organic matter 
is heated in isolation, as has been investigated for the martian regolith (e.g., Iñiguez et al., 2009).

The composition of the lunar regolith depends upon the bedrock from which it is formed and tends to be predominantly basaltic in mare regions or anorthositic in highland areas (McKay et al., 1991). As such, the regolith is chiefly composed of a complex mixture of rock fragments and grains containing plagioclase feldspar, olivine, and pyroxene in variable amounts, as well as amorphous glass (Papike et al., 1982; McKay et al., 1991). There are also quantities of ilmenite and meteoritic iron. Elemental iron also occurs as a nanoparticle distribution within the amorphous glass rims of grains, and in agglutinates, formed as a result of micrometeorite impacts and redistribution of Fe from lunar silicates (Keller and McKay, 1997; Taylor et al., 2001).

In this work, we performed heating experiments on various organic materials under vacuum in the presence and absence of lunar regolith analogue Johnson Space Center 1 (JSC-1) to determine any alteration effects of the minerals on the organic materials. The aim was to assess the validity of the proposed mechanism of preservation of organic materials in lunar regolith capped by lava flows. Our results can be used to direct the search for organic records of chemical and early biological evolution in the Solar System that may exist on the Moon.

\section{Materials and Methods}

A variety of organic compounds and materials were heated under vacuum at a range of temperatures with and without lunar regolith simulant present. The products were then extracted with solvent, and these extracts were analyzed by gas chromatography-mass spectrometry (GC-MS). The solvent-extracted residues were analyzed by pyrolysisgas chromatography-mass spectrometry (pyrolysis-GC-MS).

\subsection{Lunar regolith simulant}

JSC- 1 is a simulant of the lunar mare regolith and was developed to fulfill a wide range of analog roles. It is a basaltic volcanic ash from Arizona, USA, and the main mineral constituents are plagioclase feldspar, olivine, pyroxene, and amorphous glass of basaltic composition, with a median particle size of approximately $100 \mu \mathrm{m}$ (see McKay et al., 1994, and Willman et al., 1995, for a complete description of JSC-1). Although primarily intended as a geotechnical and engineering analogue, it nevertheless has a similar mineralogy and particle size distribution to lunar mare regolith. Key chemical differences include a greater abundance of water in JSC-1 as a consequence of the hydrous nature of terrestrial lavas, and a lack of $\mathrm{Fe}^{3+}$ in the lunar regolith (McKay et al., 1994). Analog materials such as JSC-1, which are available in significant quantities, are essential for exploratory work, allowing experimental insight without sacrificing valuable authentic samples.

\subsection{Organic samples}

Two types of organic materials were chosen for experimentation: free organic compounds and polymeric materials.

2.2.1. Free organic compounds. The free (solvent soluble) organic compounds selected for the heating experiments have been used before to test organic-detection instruments for life-detection missions (Table 1; Court et al., 2010). The suite of eight free compounds (hereafter termed "FC-8"), comprising atrazine, hexadecane, phytane, squalene, coprostane, stigmasterol, anthracene, and pyrene, represent a range of structures and include both biogenic compounds and compounds that can occur in the absence of life. Defining the range of temperatures that these compounds can withstand will provide insights into whether it is possible that biological organic material delivered to the Moon by terrestrial meteorites, and nonbiological material from asteroid and comet debris, could survive in the lunar surface in the lava flow trapping scenario.

2.2.2. Polymers. Both meteoritic and biotic carbonaceous materials contain a large proportion of macromolecular organic materials. Synthetic polymers were used as a simulant of this material. Poly( $\varepsilon$-caprolactone) (PCL) and poly[(R)-3-hydroxybutyrate] (PHB), which are both polyesters, were chosen. Although markedly different in structure to the meteoritic macromolecular organic material, the synthetic polymers have well-characterized mechanisms of thermal decomposition, allowing any deviations due to the presence of mineral matrix to be recognized.

\subsection{Sample preparation}

Glassware, including pyrolysis tubes, was prepared by baking in aluminum foil in air at $500^{\circ} \mathrm{C}$ for a minimum of $3 \mathrm{~h}$, or by cleaning with solvent. JSC- 1 was cleaned by exhaustive washing with dichloromethane to remove organic contaminants. The eight compounds of FC-8 were made up in $20 \mu \mathrm{L}$ of methanol, which was spiked with a syringe onto

Table 1. Free Organic Compounds Used in Heating Experiments

\begin{tabular}{lcccc}
\hline Compound & Compound type & Formula & Molecular weight & Properties relevant to this study \\
\hline Atrazine & Triazine & $\mathrm{C}_{8} \mathrm{H}_{14} \mathrm{ClN}_{5}$ & 215.68 & Control compound \\
Hexadecane & Alkane & $\mathrm{C}_{16} \mathrm{H}_{34}$ & 226.44 & Terrestrial biomarker \\
Phytane & Isoprenoid & $\mathrm{C}_{20} \mathrm{H}_{42}$ & 282.55 & Terrestrial biomarker \\
Squalene & Isoprenoid & $\mathrm{C}_{30} \mathrm{H}_{50}$ & 410.72 & Terrestrial biomarker \\
Coprostane & Sterane & $\mathrm{C}_{27} \mathrm{H}_{48}$ & 372.67 & Terrestrial biomarker \\
Stigmasterol & Sterol & $\mathrm{C}_{29} \mathrm{H}_{48} \mathrm{O}$ & 412.69 & Terrestrial biomarker \\
Anthracene & Aromatic & $\mathrm{C}_{14} \mathrm{H}_{10}$ & 178.23 & Meteoritic (carbonaceous type) \\
Pyrene & Aromatic & $\mathrm{C}_{16} \mathrm{H}_{10}$ & 202.25 & Meteoritic (carbonaceous type) \\
\hline
\end{tabular}


JSC-1, which was preloaded into a pyrolysis tube to give $20 \mu \mathrm{g}$ per compound. The methanol was then removed by thorough drying at $37^{\circ} \mathrm{C}$. The spiking process resulted in a total organic content of $0.5-0.8 \mathrm{wt} \%$. For those experiments where FC-8 was heated in the absence of JSC-1, the $20 \mu \mathrm{L}$ of FC-8 methanol solution was spiked onto quartz wool in a quartz pyrolysis tube to give $20 \mu \mathrm{g}$ per individual compound, before the methanol was evaporated by using a hot box at $37^{\circ} \mathrm{C}$. The quartz wool was intended to act as a simple substrate to retain the compounds; therefore a precise ratio of compound mass to quartz wool mass was not applied. To check for contamination, aliquots of JSC-1 ( 25$40 \mathrm{mg}$ each) containing no added organic material were heated alongside the other samples at each temperature step.

Finely powdered polymers were mixed with JSC-1 to give approximately $5 \mathrm{wt} \%$ organic content. Approximately 20-30 mg of this mixture was then loaded into quartz pyrolysis tubes and secured with quartz wool at both ends. For organic samples heated without JSC-1, variable masses from 2 to $12 \mathrm{mg}$ were loaded into pyrolysis tubes in the same manner.

For each individual experiment, the quartz pyrolysis tube with loaded sample was placed into a $200 \mathrm{~mm}$ length of $3 \mathrm{~mm}$ internal diameter borosilicate glass tubing sealed at one end with a flame. The unsealed end of the tube was connected to a vacuum line and evacuated before the whole tube was flame sealed. Care was taken to ensure that the heat from the flame sealing process did not affect the loaded sample. The vacuum sealing process will have removed the majority of atmospheric and adsorbed water.

\subsection{Heating experiments}

Sample tubes were heated in a furnace from room temperature $\left(\sim 20^{\circ} \mathrm{C}\right)$ up to the required final temperature at a rate of $1^{\circ} \mathrm{C} \min ^{-1}$. The final temperature was held for $80 \mathrm{~min}$; then the furnace was allowed to cool. This temperature profile was intended to simulate the gradual heating of regolith material beneath a recently emplaced lava flow up to a maximum temperature. The four maximum temperatures chosen were $250^{\circ} \mathrm{C}, 400^{\circ} \mathrm{C}, 550^{\circ} \mathrm{C}$, and $700^{\circ} \mathrm{C}$. The chosen temperatures can be considered to correspond to a range of depths into the regolith beneath the lava flow. A thicker overlying lava flow will mean a greater temperature excursion at a given depth than for a thinner lava flow, and it will also remain hotter for longer owing to the greater volume of lava (Fagents et al., 2010; Rumpf et al., 2013). The minimum observed thickness of individual lava flow units on the Moon is $\sim 1 \mathrm{~m}$ (Vaniman et al., 1991). The maximum temperature isotherm of $700^{\circ} \mathrm{C}$ modeled by Rumpf et al. (2013) for a $1 \mathrm{~m}$ lava flow reaches a maximum depth of $\sim 0.1 \mathrm{~m}$ into the regolith beneath the lava flow after 10 days. The $300^{\circ} \mathrm{C}$ isotherm reaches a maximum depth of $\sim 0.2 \mathrm{~m}$ after 20 days. This temperature is slightly higher than the $250^{\circ} \mathrm{C}$ step used in our heating experiments but provides an indication that the peak temperatures chosen for our experiments correspond to the first few tens of centimeters depth below the surface of the regolith.

\subsection{Sample extraction}

After the sample tubes cooled, they were carefully broken open. Soluble organic compounds were then extracted from the sample and the internal glass surface of the tube by the addition of approximately $0.5 \mathrm{~mL}$ of $93: 7 \mathrm{v} / \mathrm{v}$ dichloromethane:methanol solution. The solvent extraction step was repeated a further two times to ensure complete removal of organic compounds. Subsequently, the quartz pyrolysis tube containing the sample was removed from the borosilicate tubing and was dried at $37^{\circ} \mathrm{C}$ to remove solvent.

\subsection{Analysis}

The solvent extracts were made up to $1 \mathrm{~mL}$ with dichloromethane for analysis by GC-MS. Samples were run by using an Agilent $7890 \mathrm{~N}$ gas chromatograph coupled to an Agilent 5975C mass selective detector (MSD). The injected sample volume was $1 \mu \mathrm{L}$. The oven temperature was programmed for $50^{\circ} \mathrm{C}(1 \mathrm{~min})$ then ramped at $4^{\circ} \mathrm{C} \mathrm{min}^{-1}$ up to $310^{\circ} \mathrm{C}$, and then held for $20 \mathrm{~min}$. Separation was carried out on an Agilent HP-5MS capillary column (30 m length, $250 \mu \mathrm{m}$ i.d., $0.25 \mu \mathrm{m}$ film thickness) with helium carrier gas at a flow rate of $1.1 \mathrm{~mL} \mathrm{~min}^{-1}$. The inlet was operated in splitless mode and held at $250^{\circ} \mathrm{C}$. The MSD scan range was $m / z$ 50-550.

The solvent-extracted residue in the quartz pyrolysis tube was subjected to pyrolysis-GC-MS. Analysis was carried out with a Chemical Data Systems 5200 pyroprobe coupled to an Agilent 6890 gas chromatograph with a 5973 MSD. Pyrolysis was performed at $600^{\circ} \mathrm{C}$ for $15 \mathrm{~s}$. Separation was achieved with an Agilent J\&W DB-5MS UI column $(30 \mathrm{~m}$ length, $250 \mu \mathrm{m}$ i.d., $0.25 \mu \mathrm{m}$ film thickness) with helium carrier gas at a flow rate of $1.1 \mathrm{~mL} \min ^{-1}$. The oven was held at $40^{\circ} \mathrm{C}$ for $2 \mathrm{~min}$, before being ramped to $300^{\circ} \mathrm{C}$ at a rate of $5^{\circ} \mathrm{C} \mathrm{min}{ }^{-1}$, and then held at the final temperature for $8 \mathrm{~min}$. The inlet was held at $270^{\circ} \mathrm{C}$ and operated in split mode (50:1). The MSD scan range was $m / z$ 45-550.

Compound identification was performed based on retention times, comparison with standard compounds in the case of FC-8, and mass spectra referenced in the NIST-08 mass spectrum library.

\section{Results}

Analysis of the solvent extracts and the pyrolysis-GC-MS results are complementary; the solvent extracts reveal the unbound compounds that survive the heating process, as well as those that are generated by degradation of any polymers present in the experimental residue. Pyrolysis-GCMS provides information about polymers that survive thermal processing but also newly formed polymeric structures that are created by cross-linking reactions. Solvent extraction of an $18.6 \mathrm{mg}$ split of JSC-1 (i.e., for a typical mass used for heating experiments) showed no organic components. Aliquots of JSC-1, which contained no added organic material and were heated alongside the other samples at each temperature step, showed no substantial organic contamination that would affect the interpretation of results in either the solvent extracts or pyrolysis runs.

\subsection{Free compounds (FC-8)}

3.1.1. Solvent extracts. The pattern of survival of the free organic compounds (Table 1) for samples heated with JSC-1 present and those where JSC-1 was absent are similar. In both cases, at the lowest heating step of $250^{\circ} \mathrm{C}$, stigmasterol and atrazine are lost (Table 2). Squalene has a 
Table 2. Summary of the Products of the Heating Experiments Using FC-8 (See Table 1)

\begin{tabular}{|c|c|c|c|c|}
\hline \multirow{2}{*}{$\begin{array}{l}\text { Temperature of heating } \\
\text { experiment }\left({ }^{\circ} \mathrm{C}\right)\end{array}$} & \multirow{2}{*}{$\begin{array}{l}\text { Matrix } \\
\text { type }\end{array}$} & \multirow{2}{*}{$\begin{array}{l}\text { Mass of } \\
\text { matrix (mg) }\end{array}$} & \multicolumn{2}{|c|}{ Compounds detected } \\
\hline & & & Solvent soluble & Pyrolysis \\
\hline \multirow[t]{2}{*}{20} & None & - & n.d. & n.d. \\
\hline & JSC-1 & 20.8 & $\underset{\text { Sti }}{\text { Hex, Phy, Cop, An, Py, At, Sq, }}$ & n.d. \\
\hline \multirow{2}{*}{250} & None & - & Hex, Phy, Cop, An, Py, Sq & Phy \\
\hline & JSC-1 & 27.6 & Hex, Phy, Cop, An, Py & Hex, Phy \\
\hline \multirow[t]{2}{*}{400} & None & - & $\begin{array}{l}\text { Hex, Phy, Cop, An, Py, break } \\
\text { down products of Sti, aliphatic } \\
\text { fragments }\end{array}$ & Hex, Phy \\
\hline & JSC-1 & 22.5 & Hex, Phy, Cop, An, Py & $\begin{array}{l}\text { Hex, Phy, An (tentative), TMN } \\
\text { and cyclic, aromatic, and } \\
\text { aliphatic fragments (tentative) }\end{array}$ \\
\hline \multirow[t]{2}{*}{550} & None & - & An, Py, PAH $m / z, 192$ & None \\
\hline & JSC-1 & 28.3 & An, Py & $\begin{array}{l}\text { MN, DMN, TMN (tentative), } \\
\text { PAH } m / z .178\end{array}$ \\
\hline \multirow[t]{2}{*}{700} & None & - & None & None \\
\hline & JSC-1 & 31.7 & None & $\mathrm{N}$, PAH $m / z 178$ \\
\hline
\end{tabular}

An, anthracene; At, atrazine; Cop, coprostane; DMN, dimethylnaphthalene; Hex, hexadecane; MN, methylnaphthalene; N, naphthalene; PAH $\mathrm{m} / z$ \#, polycyclic aromatic hydrocarbon with $\mathrm{m} / \mathrm{z}$, ratio for main response indicated; Phy, phytane; Py, pyrene; Sq, squalene; Sti, stigmasterol; TMN, trimethylnaphthalene; n.d., not determined.

very low response where JSC-1 is absent and was not detected when JSC-1 was present. At $550^{\circ} \mathrm{C}$, only anthracene and pyrene remain in both the sample heated with JSC-1 and the one without. After the heating experiments at $700^{\circ} \mathrm{C}$, none of the original compounds of FC- 8 are detectable in the total ion chromatogram. Aromatization of the FC-8 compounds also occurred, as evidenced by a methylated 3ringed $(\mathrm{m} / \mathrm{z}, 192)$ aromatic compound in the $550^{\circ} \mathrm{C}$ sample heated without JSC-1.

3.1.2. Pyrolysis products. Up to $400^{\circ} \mathrm{C}$, the key products detected by pyrolysis-GC-MS were hexadecane and phytane. It is likely that these compounds were incompletely removed by solvent extraction. At the $550^{\circ} \mathrm{C}$ temperature step, new compounds that were not initially present in the FC-8 were detected in the JSC-1 sample. Methyl-, dimethyl-, and trimethylnaphthalene are indicative that a temperature of $550^{\circ} \mathrm{C}$ is sufficient to cause aromatization of the constituent compounds of FC-8. This is reflected in the formation of a methylated aromatic compound $(\mathrm{m} / \mathrm{z} 192)$, which was detected in the solvent extract of FC-8 heated at $550^{\circ} \mathrm{C}$ in the absence of JSC-1. At $700^{\circ} \mathrm{C}$, in the sample heated with JSC-1, only naphthalene and a 3-ringed polycyclic aromatic hydrocarbon $(\mathrm{PAH})(\mathrm{m} / \mathrm{z}, 178)$ are detectable. The increased level of condensation at the higher temperature is indicated by the lack of alkylated aromatic compounds. No compounds with a response allowing definite identification were found where FC- 8 had been heated in the absence of $\mathrm{JSC}-1$ at $550^{\circ} \mathrm{C}$ or $700^{\circ} \mathrm{C}$. It is also possible that the analytical pyrolysis temperature of $600^{\circ} \mathrm{C}$ was not sufficiently high to completely access the refractory carbonaceous phase formed by heating at $700^{\circ} \mathrm{C}$.

\subsection{Polymers: poly( $\varepsilon$-caprolactone)}

3.2.1. Solvent extracts. The solvent extracts of PCL heated with and without JSC- 1 at $250^{\circ} \mathrm{C}$ both show systematic breakdown products and do not display any ma- jor differences (Fig. 1a). Analysis of the solvent extracts from the experiments at $250^{\circ} \mathrm{C}$ is complicated by the solubility of the surviving polymer in solvent. Upon injection, the solubilized polymer can break down in the inlet of the gas chromatograph. This was confirmed by the generation of the same products where PCL mixed with JSC-1 was subject to solvent extraction without prior heating. Following heating at $400^{\circ} \mathrm{C}$, a more complex assemblage of polymer fragments is produced. However, following heating at $550^{\circ} \mathrm{C}$, the dominant response in the solvent extracts of both samples is pyrene $(\mathrm{m} / \mathrm{z} 202)$. Polycyclic aromatic compounds up to $m / z 290$ are detectable in the solvent extract of PCL heated without JSC-1 (Fig. 1a). In the solvent extract following heating at $700^{\circ} \mathrm{C}$ without JSC-1, a range of aromatic compounds were detected including naphthalene, biphenyl, fluoranthene, pyrene, and an aromatic compound with $m / z$ 252. There are no peaks in the total ion chromatogram of the solvent extract from the experiment where PCL was heated with JSC-1 at $700^{\circ} \mathrm{C}$.

3.2.2. Pyrolysis products of residues. Following heating at $250^{\circ} \mathrm{C}, 2$-oxepanone and hexenoic acids indicate the presence of surviving PCL polymer. These are products of unzipping reactions and cis-elimination of the polymer (Persenaire et al., 2001; Aoyagi et al., 2002). Comparing the pyrolysis-GC-MS results of PCL heated with and without JSC-1 present at $250^{\circ} \mathrm{C}$ reveals that there is a slightly greater diversity of products released from the residual polymer when JSC-1 is present (Fig. 1b).

At $400^{\circ} \mathrm{C}$, pyrolysis-GC-MS generates a much greater diversity of products from the residual polymer. The product with the greatest response for both the sample heated with JSC-1 and the one without was hexenoic acid. The broad "fingerprint" of the chromatograms was similar between the two; however, the sample heated with JSC-1 showed greater responses for benzene and alkylbenzenes relative to hexenoic acid than the sample without (Fig. 1b). 
This indicates that aromatization of the polymer is facilitated by the presence of the mineral matrix. At $550^{\circ} \mathrm{C}$, aromatization of both samples is more complete. However, the proportion of di- and trimethylnaphthalenes and fluorene relative to naphthalene is much greater in the sample heated with JSC-1 than the one without (Fig. 1b). Responses at $\mathrm{m} / \mathrm{z} 178$ that correspond to the 3-ring $\mathrm{PAH}$ anthracene and phenanthrene are minor in the pyrolysisGC-MS chromatograms for both samples, and 4-ring or larger aromatic PAHs were not detected, indicating that

a Solvent extracts of poly( $\varepsilon$-caprolactone)

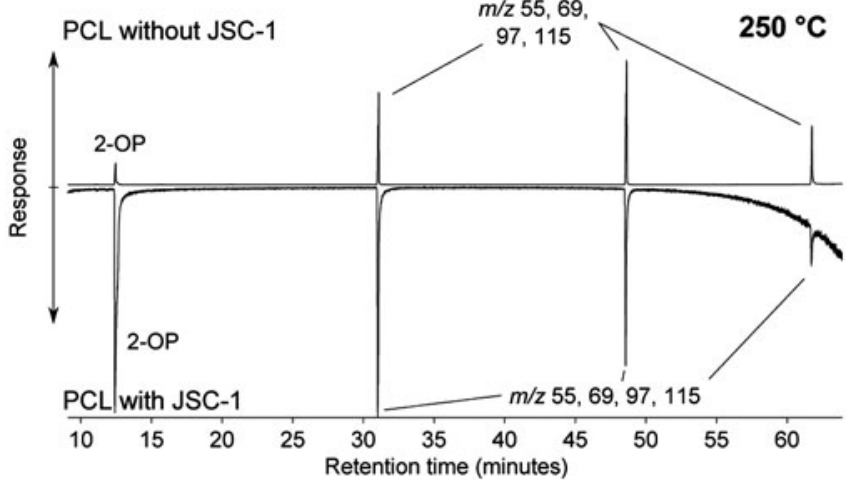

PCL without JSC-1

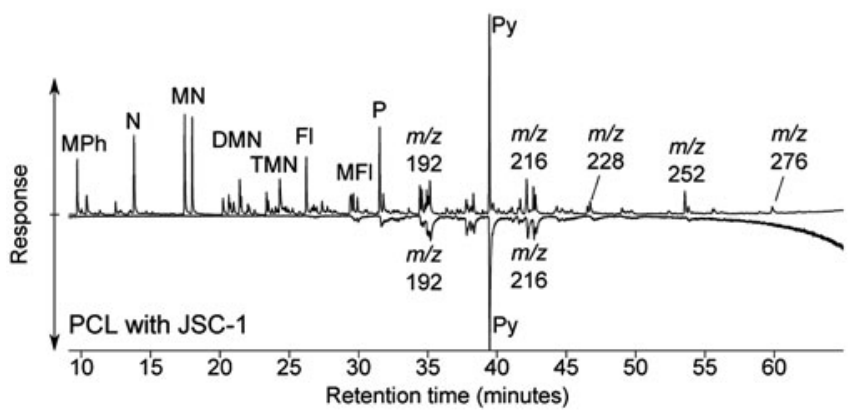

b Pyrolysis of residues of poly( $\varepsilon$-caprolactone)

PCL without JSC-1

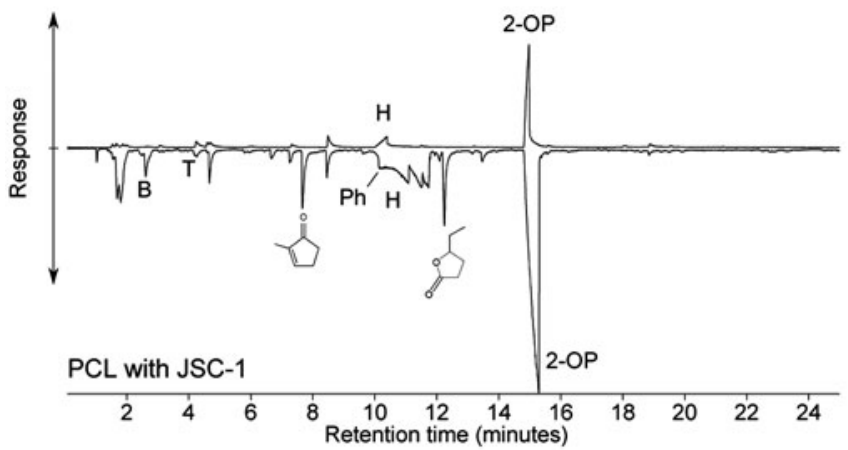

PCL without JSC-1

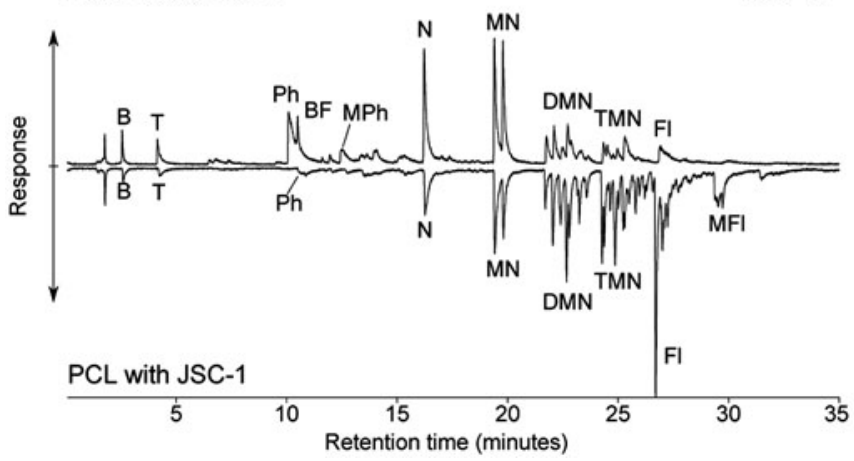

PCL without JSC-1

$400{ }^{\circ} \mathrm{C}$

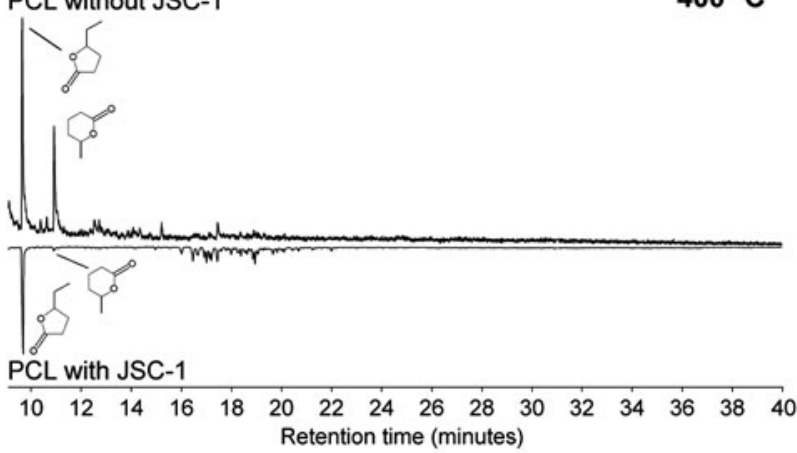

PCL without JSC-1

$700^{\circ} \mathrm{C}$

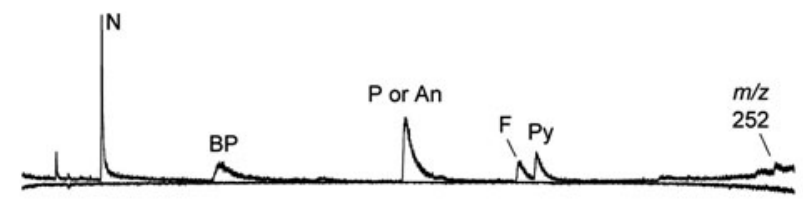

PCL with JSC-1

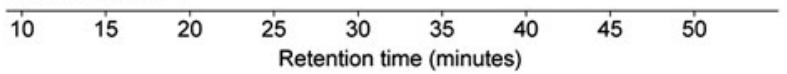

PCL without JSC-1

$400^{\circ} \mathrm{C}$

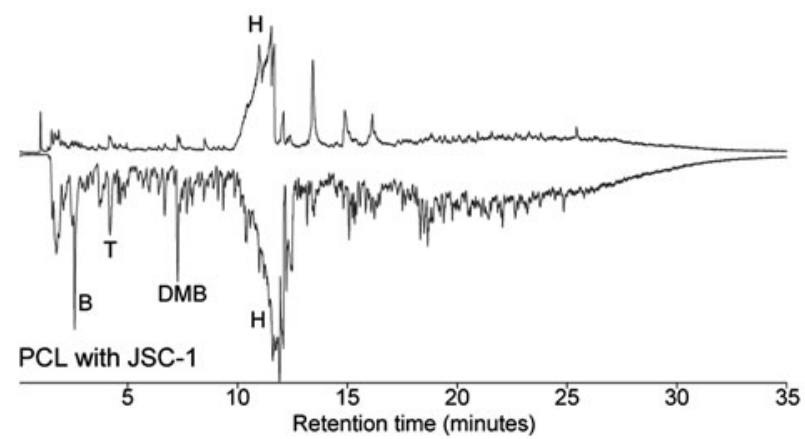

PCL without JSC-1

$700^{\circ} \mathrm{C}$

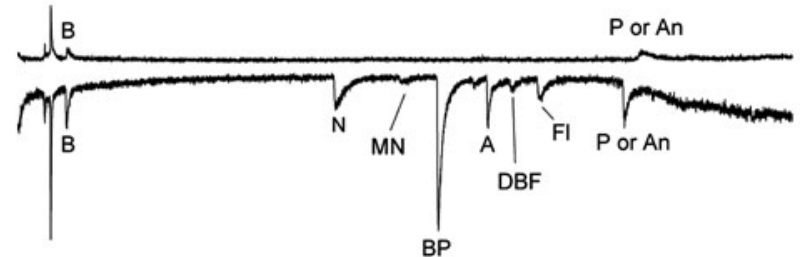

PCL with JSC-1

$$
\begin{array}{lccccc}
15 & 20 & 25 & 30 & 35 & 40 \\
\text { Retention time (minutes) }
\end{array}
$$


while relatively large free aromatic compounds are released during the heating experiments, the polymer residue is composed of smaller aromatic units.

After heating PCL without JSC- 1 at $700^{\circ} \mathrm{C}$, only benzene and a response at $\mathrm{m} / \mathrm{z}, 178$ are detectable in the pyrolysisGC-MS total ion chromatogram, indicating that the polymer residue has been further condensed relative to the previous temperature step. In the pyrolysis-GC-MS total ion chromatogram for the sample of PCL heated with JSC-1, benzene, naphthalene, biphenyl, and anthracene or phenanthrene are detectable, along with minor responses for alkylated aromatic compounds.

\subsection{Polymers: polyhydroxybutyrate}

3.3.1. Solvent extracts. The thermal decomposition of PHB follows a broadly similar pattern to that of PCL (Fig. 2a). After heating at $250^{\circ} \mathrm{C}$, the solvent extracts of PHB with and without JSC-1 show the presence of crotonic acid and its oligomers, which are produced from the polymer as a result of cis-elimination reactions. Crotonic acid is recognized by characteristic $m / z, 68,69$, and 86 responses (Aoyagi et al., 2002). However, these products are again likely to be at least partly the result of solubilized polymer breaking down in the heated gas chromatograph inlet.

At $400^{\circ} \mathrm{C}$, both the pyrolysis-GC-MS and solvent extract chromatograms reveal a wide range of products with an unresolvable complex mixture (Fig. 2a, 2b). However, there are some differences in the responses of individual compounds in the solvent extracts. A peak with signals at $m / z 67$, 136, 154 gives a greater relative response in the PHB heated without JSC-1, and the compound gives a major response in the pyrolysis-GC-MS chromatogram where JSC-1 was present. This may be due to incomplete extraction of the compound from the minerals by solvent extraction. Another two peaks, one with signals at $\mathrm{m} / \mathrm{z}, 99$ and the other at $\mathrm{m} / \mathrm{z}$ 110 and 152, are prominent in the solvent extract of the sample heated with JSC-1 but are minor peaks in the PHB sample heated in isolation (Fig. 2a). After heating of PHB without JSC- 1 at $550^{\circ} \mathrm{C}$, the solvent extract is very similar to that of PCL heated in isolation at the same temperature, with a broad range of condensed and alkylated aromatic compounds present. The key responses are for naphthalene, methylnaphthalenes, and pyrene. However, the solvent extract of PHB heated with JSC- 1 at $550^{\circ} \mathrm{C}$ shows a different pattern to that of PHB heated on its own. Where JSC-1 is present, pyrene is a weak response, and methylphenol is a strong response relative to naphthalene. Where JSC-1 is ab- sent, pyrene is a strong response, and methylphenol is a weak response relative to naphthalene. The polymer has interacted with the mineral matrix to produce a different distribution of organic products. As with PCL, low responses of simple aromatic compounds are detected in the solvent extract chromatograms and pyrolysis-GC-MS chromatograms of PHB heated both with and without JSC- 1 at $700^{\circ} \mathrm{C}$.

3.3.2. Pyrolysis products of residues. Pyrolysis-GC-MS of the residue of PHB heated with JSC-1 at $250^{\circ} \mathrm{C}$ also shows crotonic acid; no crotonic acid was detected by pyrolysis-GC-MS where PHB was heated in isolation. The pyrolysis-GC-MS chromatograms of the residues of the PHB heated at $550^{\circ} \mathrm{C}$ also show a similar pattern to the PCL samples. After heating with JSC-1, the residual PHB polymer gives a greater pyrolysis-GC-MS response for di- and trimethylnaphthalenes and fluorene relative to naphthalene than when PHB is heated in isolation. There is also a strong response for methylphenol relative to naphthalene in the pyrolysate where JSC-1 is present, concordant with the strong methylphenol response in the corresponding solvent extract.

\section{Discussion}

\subsection{Alteration of organic materials in a lunar regolith simulant}

We performed heating experiments to determine the viability of preserving organic compounds in lunar regolith material beneath a lava flow. Particularly, we tested to see whether the lunar regolith, simulated by JSC-1 analog material, has any deleterious effects on the preservation of organic materials under heating.

For the free organic compounds, JSC-1 does not appear to have any dramatic destructive effect. As in the experiments without JSC-1, all compounds except atrazine, squalene, and stigmasterol are detectable after the $400^{\circ} \mathrm{C}$ experiment. FC8 comprises a variety of terrestrial biomarker compounds; the fact that these compounds can survive at high temperature under vacuum in the presence of lunar regolith analogue lends credibility to the possibility that biomarkers in terrestrial meteorites from early Earth could remain preserved on the Moon in regolith at tens of centimeters depth under lava flow units.

For the polymers PCL and PHB, increasing the temperature of heating firstly causes the compounds to depolymerize into monomers and oligomers at $250^{\circ} \mathrm{C}$, a process

FIG. 1. Chromatograms of (a) the solvent extracts and (b) the pyrolyzed residues of poly( $\varepsilon$-caprolactone). Chromatograms are displayed back-to-back, with the chromatogram where JSC-1 was absent on top and where it was included underneath. The temperature of the heating experiment is shown in the upper right for each chromatogram couple. At $250^{\circ} \mathrm{C}$, the systematic breakdown products of PCL are detected in the extracts and residues, before more complete breakdown of the polymer structure at $400^{\circ} \mathrm{C}$. At $550^{\circ} \mathrm{C}$ the polymer has charred, with PAHs as the dominant responses. However, the responses of the compounds in both the solvent extracts and the residues vary between the experiment where JSC-1 was present and the experiment where it was absent. At $700^{\circ} \mathrm{C}$ there are only small responses for mainly non-alkylated PAHs. Compound labels: 2-OP, 2-oxepanone; A, acenaphthene; An, anthracene; B, benzene; BF, benzofuran; BP, biphenyl; DBF, dibenzofuran; DMB, dimethylbenzene; DMN, dimethylnaphthalenes; F, fluoranthene; Fl, fluorene; H, hexenoic acids; MFl, methylfluorenes; MN, methylnaphthalenes; MPh, methylphenol; N, naphthalene; P, phenanthrene; Ph, phenol; Py, pyrene; $\mathrm{T}$, toluene; TMN, trimethylnaphthalenes. Other compounds of note are labeled with structures or principal mass spectral $\mathrm{m} / \mathrm{z}$ responses. The vertical axes of the chromatograms have been scaled to allow easier comparison; responses are nonquantitative. 
that is well characterized (Persenaire et al., 2001; Aoyagi et al., 2002). These systematic breakdown products can be seen in both the solvent extracts and the residues (Figs. 1 and 2). However, due to the nature of the analytical techniques employed, it is likely that some of the detected compounds are not primary products from the experiments

\section{a Solvent extracts of polyhydroxybutyrate}

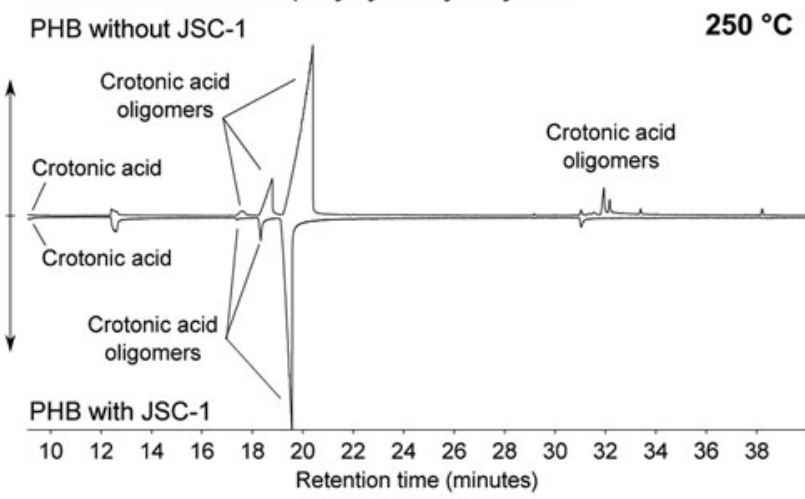

PHB without JSC-1

$550^{\circ} \mathrm{C}$

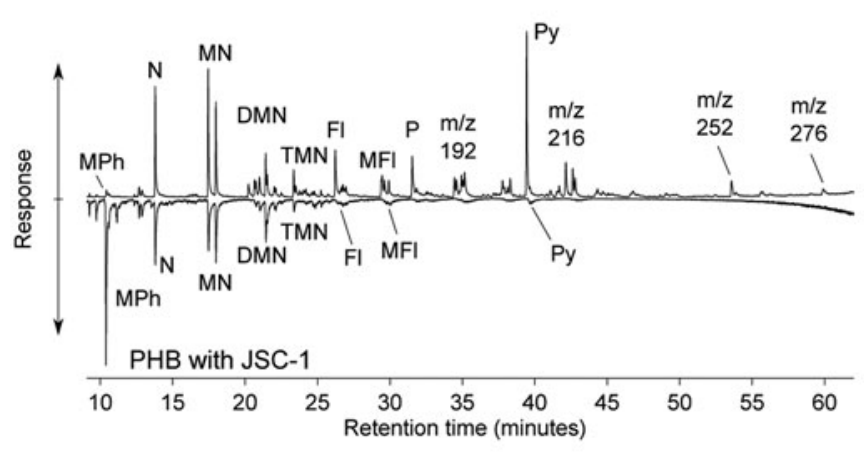

b Pyrolysis of residues of polyhydroxybutyrate PHB without JSC-1

$250^{\circ} \mathrm{C}$

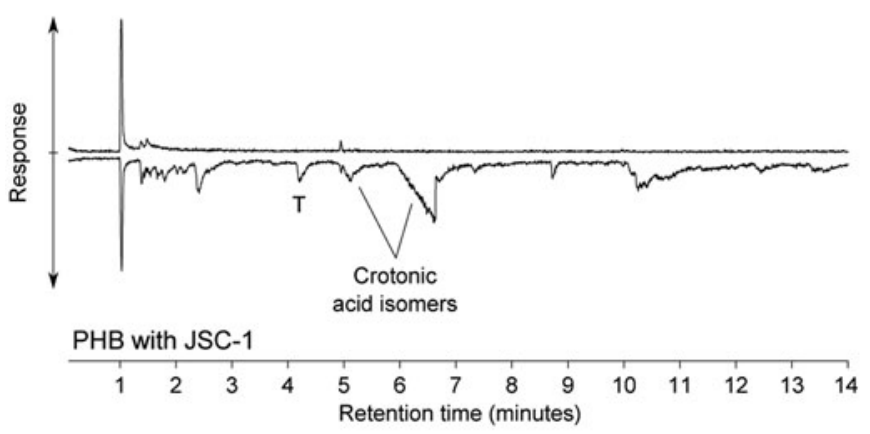

PHB without JSC-1

$550^{\circ} \mathrm{C}$

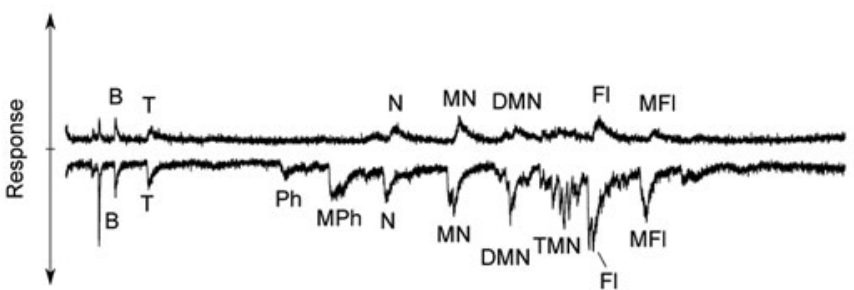

PHB with JSC-1

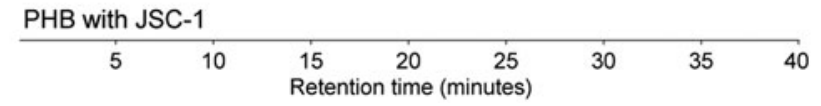

but instead result from breakdown of the solubilized polymer in the hot $\left(250^{\circ} \mathrm{C}\right)$ gas chromatograph inlet. At $400^{\circ} \mathrm{C}$, breakdown of the polymers is more complete, with a wide variety of smaller molecules being generated. At $550^{\circ} \mathrm{C}$, the polymers are charred; that is, they have been extensively aromatized by heating in the absence of oxygen, and

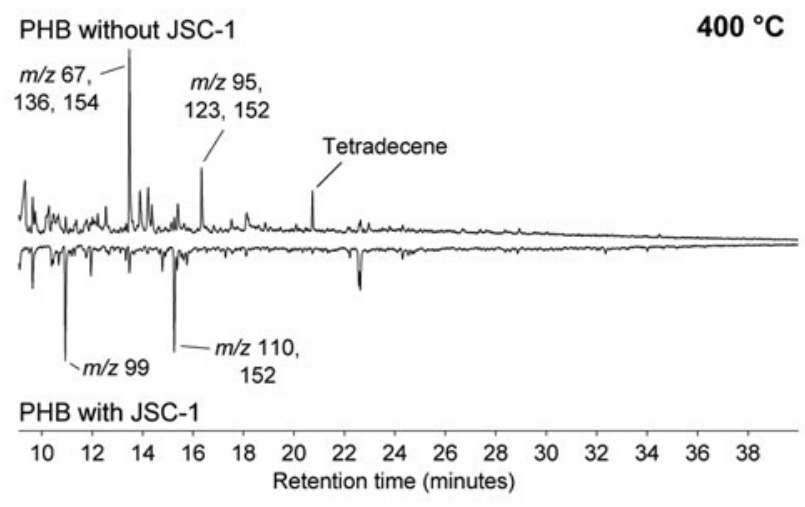

PHB without JSC-1

$700^{\circ} \mathrm{C}$

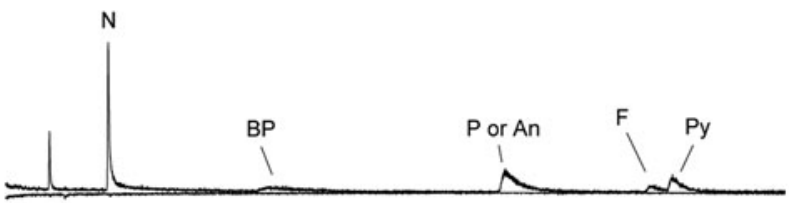

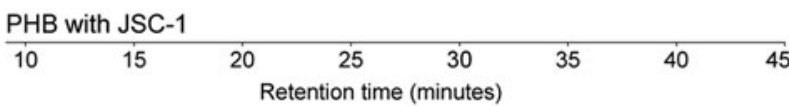

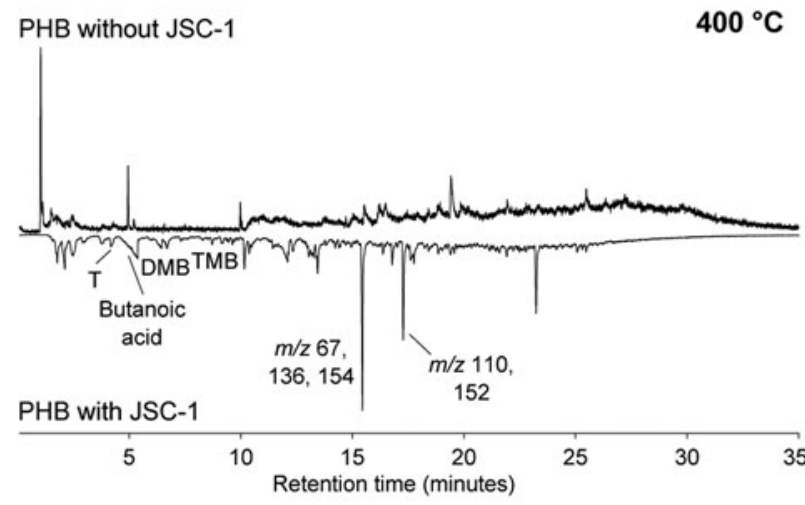

PHB without JSC-1

$700^{\circ} \mathrm{C}$

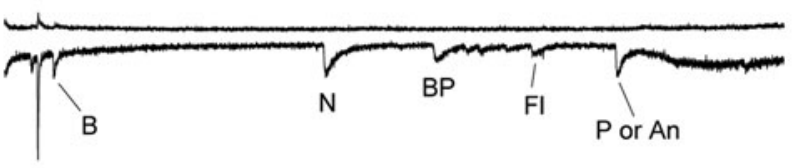

PHB with JSC-1

$\begin{array}{llcrrrrr}5 & 10 & \begin{array}{c}15 \\ \text { Retention time (minutes) }\end{array} & & 20 & 35 & 40\end{array}$


aromatic hydrocarbons are the main responses from both the solvent extracts and pyrolysis of the residues. Charring is almost complete at $700^{\circ} \mathrm{C}$, with low responses for simple aromatic hydrocarbons and a loss of compound diversity compared with the previous heating step.

It can be seen from the back-to-back comparisons of the chromatograms in Figs. 1 and 2 that the presence of JSC-1 influences the types and proportions of compounds produced at different temperatures. The pyrolysis of the residues where JSC-1 is present shows a greater variety of responses. In the pyrolysis residues at $400^{\circ} \mathrm{C}, \mathrm{JSC}-1$ appears to be promoting aromatization; benzene and alkylbenzenes are prominent relative to other responses in the chromatograms of the residues where JSC-1 was present. With both PCL and $\mathrm{PHB}$, after heating with $\mathrm{JSC}-1$ at $550^{\circ} \mathrm{C}$, the residual polymer, when subject to pyrolysis-GC-MS, releases a greater proportion of alkylated napthalenes relative to naphthalene than when the polymers were heated in isolation. The distribution and responses of soluble aromatic compounds generated from PHB and PCL heated in isolation at $550^{\circ} \mathrm{C}$ are very similar; however, it can be seen that the presence of JSC-1 alters the distribution of responses of the generated compounds (Figs. 1a and 2a). It is apparent that the presence of the JSC-1 material affects the ability of the dichloromethane:methanol solvent to efficiently extract soluble organic compounds from the samples after the heating experiments, complicating interpretation of the results. However, particularly in the case of the aromatic compounds generated at the $550^{\circ} \mathrm{C}$ step for the synthetic polymers, a range of distributions of responses is seen that cannot be attributed to solvent extraction efficiencies and is instead a result of organic-mineral interactions during the heating experiments. The chromatograms of the PCL and PHB polymers at the $700^{\circ} \mathrm{C}$ step show similar behavior. Where JSC-1 was absent, there are readily detectable aromatic compounds in the solvent extracts; however, this is not the case where JSC-1 was present. Conversely, a wider variety of aromatic compounds are present in the pyrolyzed residues of the polymers where JSC-1 was present. The data indicate that the mineral and glass surfaces of JSC-1 are adsorbing and retaining the products of aromatization. The JSC-1 lunar analogue consists of a mixture of different mineral types, the main constituents being feldspar, pyroxene, and olivine. The catalytic properties of these minerals have been investigated in a number of industrial and natural settings (e.g., Rapagnà et al., 2000; Demiral and Şensöz, 2008; Tian et al., 2013). However, for this study we simply

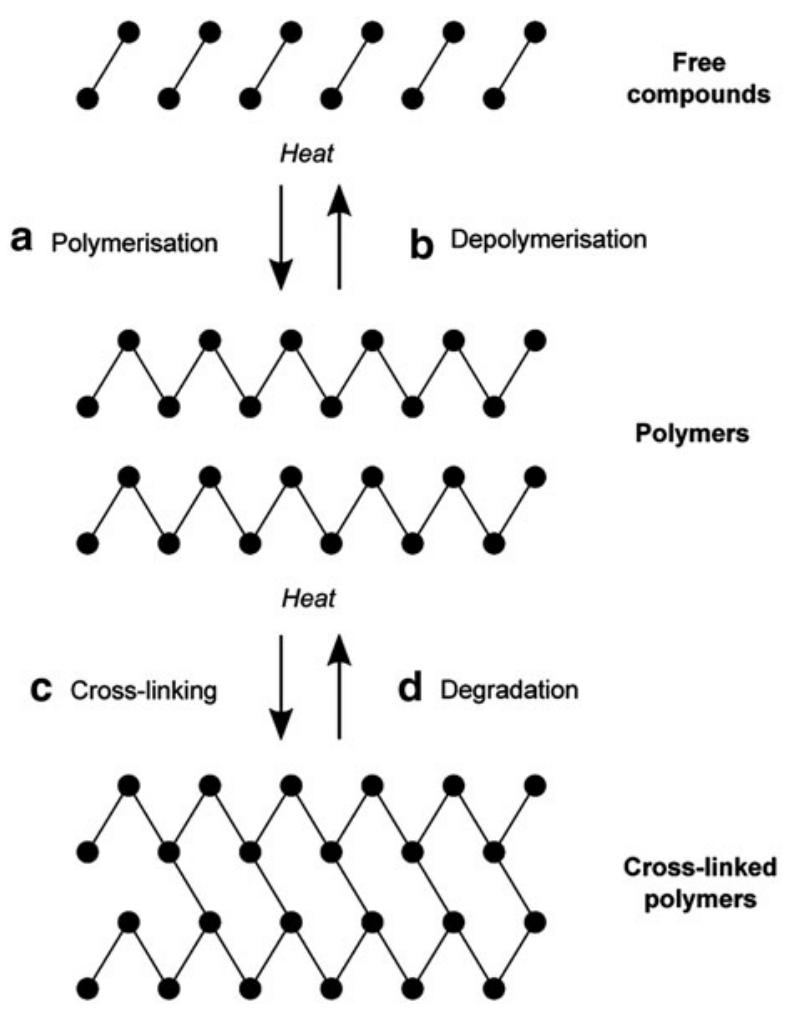

FIG. 3. Schematic summarizing the processes occurring during heating of the organic compounds. The relevant chemical reactions can be divided into four processes: (a) polymerization of free compounds into polymers, (b) depolymerization of polymers into free compounds and gases, (c) cross linking of polymers to form more intractable organic residues, and (d) degradation of cross-linked polymers into polymers, fragments of polymers (oligomers), or free compounds and gases.

focused on the overall effects of the natural JSC-1 mineral assemblage as a representative of reactions that may occur in the lunar regolith.

\subsection{General mechanism}

The results from the heating experiments with free compounds and with polymers can be synthesized into a general mechanism (Fig. 3). The lunar regolith simulant appears to promote polymerization and cross linking

FIG. 2. Chromatograms of (a) the solvent extracts and (b) the pyrolyzed residues of polyhydroxybutyrate. Chromatograms are displayed back-to-back, with the chromatogram where JSC-1 was absent on top and where it was included underneath. The temperature of the heating experiment is shown in the upper right for each chromatogram couple. As for PCL, systematic breakdown products occur in the extracts and residues at $250^{\circ} \mathrm{C}$, before more complete breakdown takes place at $400^{\circ} \mathrm{C}$. At this temperature, there are some differences in the proportions of the response of products on the chromatograms, indicating that the presence of JSC-1 is having an effect on the thermal degradation of the polymer. At $550^{\circ} \mathrm{C}$, PAHs are the main responses in the extracts and residues, with PAHs up to $\mathrm{m} / \mathrm{z} 290$ detectable. As with the PCL polymer, the presence of JSC-1 has affected the distribution of responses of compounds in both the extract and the residue. At $700^{\circ} \mathrm{C}$, low responses of simple PAHs are detectable. An, anthracene; BP, biphenyl; DMB, dimethylbenzene; DMN, dimethylnaphthalenes; F, fluoranthene; Fl, fluorene; MFl, methylfluorene; MN, methylnaphthalenes; MPh, methylphenol; $\mathrm{N}$, naphthalene; $\mathrm{P}$, phenanthrene; $\mathrm{Ph}$, phenol; $\mathrm{Py}$, pyrene; T, toluene; TMB, trimethylbenzene; TMN, trimethylnaphthalene. Other compounds of note are labeled with key mass spectral $\mathrm{m} / \mathrm{z}$ responses. The vertical axes of the chromatograms have been scaled to allow easier comparison; responses are nonquantitative. 
(reflected by the production of more diverse pyrolysis products at lower heating experiment temperatures) and retard degradation and depolymerization (indicated by the continued production of pyrolysis products at high heating experiment temperatures; the mineral surface must be acting as a protective adsorbent). The lunar regolith with a similar basaltic chemistry, glass content, and grain size as the JSC-1 simulant may, therefore, aid in the preservation of its organic matter when encapsulated and heated by lava flows.

\subsection{Preservation of organic materials in a lava-capped regolith layer}

Thermal alteration of organic matter can be considered to have both positive and negative impacts in the context of preservation. Thermal alteration of an assemblage of organic molecules destroys information about the nature of the original material, but the process of aromatization and polymerization renders the organic material more resistant to damaging environmental processes. It may in fact be a requirement to have a moderate level of alteration of organic material to a more robust aromatic structure in order to ensure long-term survival in an energetic environment.

An ideal scenario for the preservation of organic materials within paleoregolith layers has a number of competing factors. While it would be advantageous to reduce the surface exposure time of organic-containing rock fragments to a minimum to protect from radiation and impacts, there nevertheless needs to be a sufficient elapse of time to build up a regolith layer thick enough to effectively insulate against the overlying lava flow (Fagents et al., 2010; Rumpf et al., 2013). There also needs to be time to allow the organic-containing material to build up in the regolith to a concentration sufficient that a drill core (or other sampling technique) will have a reasonable chance of intercepting a useful quantity of the material. Understanding the role of radiation in the alteration of organic matter will, therefore, be extremely informative in refining the model. It has been well established that ionizing radiation can have a variety of effects on organic materials (Lewan and Buchardt, 1989; Bernstein et al., 2003; Court et al., 2006; Kminek and Bada, 2006; Dartnell, 2011).

Duration of heating in the lava flow paleoregolith model is another key consideration. Modeling studies (Fagents et al., 2010; Rumpf et al., 2013) show that the regolith can remain at temperatures substantially elevated above ambient for timescales up to months, which is substantially longer than the durations employed in the experiments described here. The minimum lava flow thickness observed on the Moon is approximately $1 \mathrm{~m}$ (Vaniman et al., 1991); however, many lunar lava flows are known to be substantially thicker than this. Thicker lava flows would increase both the duration of heating and the depth of heating into the underlying regolith (Fagents et al., 2010; Rumpf et al., 2013). Thicker lava flows also have the potential to overprint the thermal profile of thinner lava flows and regolith horizons lying beneath. These factors would increase the degree of thermal alteration of the organic matter compared to a thinner flow. Although not explored in this work because of the generally accepted anhydrous nature of lunar surface materials in regoliths between latitudes $<70^{\circ}$, water may also play a role in preservation. In terrestrial environments, the presence of water has a substantial effect on how organic matter is preserved (e.g., Killops and Killops, 2005). This also extends to space environments: the parent asteroidal bodies from which type 1 and 2 carbonaceous chondrites originated have experienced varying levels of aqueous alteration that has affected the composition and structure of the organic material (e.g., Sephton et al., 2004b). The Moon is essentially an anhydrous environment, although local sources of hydration may be provided by the hydrated silicate minerals of meteorites (Court and Sephton, 2014), hydrated volcanic pyroclastic glass beads (Saal et al., 2008, 2013; Hauri et al., 2011), indigenous minerals like apatite, and implanted solar wind (Pieters et al., 2009; for reviews see Anand et al., 2014, and Robinson and Taylor, 2014).

When subjected to heating by volcanic or other processes, water can be driven from these minerals. The released water can then interact with other materials within the host regolith. Recent observations have suggested the presence of water ice in permanently shadowed craters at the poles of the Moon (Colaprete et al., 2010). This water, which may be exogenous or endogenous in origin, could host organic compounds (Pierazzo and Chyba, 1999; Lucey, 2000). It is, therefore, important to take the role of water into account when considering the preservation of organic materials on the Moon. For the experiments in this study, although vacuum sealing of the samples before heating removed the majority of the water from the vessel, it is likely that minor amounts of atmospheric water remained adsorbed on mineral surfaces. Water may also have been released from clays in the JSC-1 analogue; however, since clay is a minor mineral phase (McKay et al., 1994), the quantity of water released from this source is assumed to be low. In the case of the synthetic polymers PCL and PHB, water would be eliminated from the polymer structure during thermal degradation (Persenaire et al., 2001) and would be available for reaction with other products or the polymer residue.

\section{Conclusions}

We have shown that organic matter is capable of surviving within a chemical and physical analogue of the lunar regolith, even when subjected to a demanding thermal regime intended to simulate the effects of an overlying flow of lava. However, we have seen that the aromatization of polymers is affected by the presence of the mineral matrix, producing a different distribution of responses for individual products than where compounds were heated on their own.

Using a range of heating temperatures intended to simulate different depths in the regolith beneath a lava flow, we have shown that for a $1 \mathrm{~m}$ thick flow, organic compounds have the potential to survive in regolith only a few tens of centimeters deep, due to the highly insulating properties of the lunar soil. These include compounds of biological origin, indicating the potential for biomarkers to be preserved in terrestrial meteorites on the Moon. Our work suggests that the paleoregolith of the lifeless Moon may be a valuable location to search for records of organic chemical evolution in the early Solar System and, perhaps, the transition from prebiotic to biotic processes on early Earth.

\section{Acknowledgments}

This work was supported by the Leverhulme Trust grant RPG-2012-581 to M.A.S., I.A.C., and A.P.J. R.W.C. was 
supported by a UK Space Agency Aurora fellowship. K.H.J. is supported by Leverhulme Trust grant ECF-2011-569. We would like to thank the reviewers for their helpful comments.

\section{Author Disclosure Statement}

The authors declare they have no competing interests.

\section{References}

Abell, P.I., Draffan, G.H., Eglinton, G., Hayes, J.M., Maxwell, J.R., and Pillinger, C.T. (1970) Organic analysis of the returned lunar sample. Science 167:757-759.

Alexander, C.M.O.D., Russell, S.S., Arden, J.W., Ash, R.D., Grady, M.M., and Pillinger, C.T. (1998) The origin of chondritic macromolecular organic matter: a carbon and nitrogen isotope study. Meteorit Planet Sci 33:603-622.

Anand, M., Tartèse, R., and Barnes, J.J. (2014) Understanding the origin and evolution of water in the Moon through lunar sample studies. Philos Trans A Math Phys Eng Sci 372, doi:10.1098/rsta.2013.0254.

Aoyagi, Y., Yamashita, K., and Doi, Y. (2002) Thermal degradation of poly[(R)-3-hydroxybutyrate], poly[e-caprolactone], and poly[(S)-lactide]. Polym Degrad Stab 76:53-59.

Armstrong, J.C. (2010) Distribution of impact locations and velocities of Earth meteorites on the Moon. Earth Moon Planets 107:43-54.

Armstrong, J.C., Wells, L.E., and Gonzalez, G. (2002) Rummaging through Earth's attic for remains of ancient life. Icarus 160:183-196.

Bernstein, M.P., Sandford, S.A., Allamandola, L.J., Chang, S., and Scharberg, M.A. (1995) Organic compounds produced by photolysis of realistic interstellar and cometary ice analogs containing methanol. Astrophys $J$ 454:327-344.

Bernstein, M.P., Moore, M.H., Elsila, J.E., Sandford, S.A., Allamandola, L.J., and Zare, R.N. (2003) Side group addition to the polycyclic aromatic hydrocarbon coronene by proton irradiation in cosmic ice analogs. Astrophys $J$ 582:L25-L29.

Bibring, J.P., Burlingame, A.L., Chaumont, J., Langevin, Y., Maurette, M., and Wszolek, P.C. (1974) Simulation of lunar carbon chemistry: I. Solar wind contribution. In Proceedings of the Fifth Lunar Science Conference, Vol. 2, Lunar and Planetary Institute, Houston, pp 1747-1762.

Bishop, A.N. and Abbott, G.D. (1993) The interrelationship of biological marker maturity parameters and molecular yields during contact metamorphism. Geochim Cosmochim Acta 57:3661-3668.

Bishop, A.N. and Abbott, G.D. (1995) Vitrinite reflectance and molecular geochemistry of Jurassic sediments: the influence of heating by Tertiary dykes (northwest Scotland). Org Geochem 22:165-177.

Botta, O. and Bada, J.L. (2002) Extraterrestrial organic compounds in meteorites. Surveys in Geophysics 23:411-467.

Bottke, W.F., Vokrouhlicky, D., Minton, D., Nesvorny, D., Morbidelli, A., Brasser, R., Simonson, B., and Levison, H.F. (2012) An Archaean heavy bombardment from a destabilized extension of the asteroid belt. Nature 485:78-81.

Brinton, K.L.F. and Bada, J.L. (1996) A reexamination of amino acids in lunar soils: implications for the survival of exogenous organic material during impact delivery. Geochim Cosmochim Acta 60:349-354.

Burchell, M.J., Parnell, J., Bowden, S.A., and Crawford, I.A. (2010) Hypervelocity impact experiments in the laboratory relating to lunar astrobiology. Earth Moon Planets 107:55-64.
Burchell, M.J., Bowden, S.A., Cole, M., Price, M.C., and Parnell, J. (2014a) Survival of organic materials in hypervelocity impacts of ice on sand, ice, and water in the laboratory. Astrobiology 14:473-485.

Burchell, M.J., McDermott, K.H., Price, M.C., and Yolland, L.J. (2014b) Survival of fossils under extreme shocks induced by hypervelocity impacts. Philos Trans A Math Phys Eng Sci 372, doi:10.1098/rsta.2013.0190.

Burlingame, A.L., Calvin, M., Han, J., Henderson, W., Reed, W., and Simoneit, B.R. (1970) Lunar organic compounds: search and characterisation. Science 167:751-752.

Colaprete, A., Schultz, P., Heldmann, J., Wooden, D., Shirley, M., Ennico, K., Hermalyn, B., Marshall, W., Ricco, A., Elphic, R.C., Goldstein, D., Summy, D., Bart, G.D., Asphaug, E., Korycansky, D., Landis, D., and Sollitt, L. (2010) Detection of water in the LCROSS ejecta plume. Science 330:463-468.

Court, R.W. and Sephton, M.A. (2014) New estimates of the production of volatile gases from ablating carbonaceous micrometeoroids at Earth and Mars during an E-belt-type late heavy bombardment. Geochim Cosmochim Acta 145:175-205.

Court, R.W., Sephton, M.A., Parnell, J., and Gilmour, I. (2006) The alteration of organic matter in response to ionising irradiation: chemical trends and implications for extraterrestrial sample analysis. Geochim Cosmochim Acta 70:1020-1039.

Court, R.W., Baki, A.O., Sims, M.R., Cullen, D., and Sephton, M.A. (2010) Novel solvent systems for in situ extraterrestrial sample analysis. Planet Space Sci 58:1470-1474.

Crawford, I.A., Baldwin, E.C., Taylor, E.A., Bailey, J.A., and Tsembelis, K. (2008) On the survivability and detectability of terrestrial meteorites on the Moon. Astrobiology 8:242252.

Crawford, I.A., Fagents, S.A., Joy, K.H., and Rumpf, M.E. (2010) Lunar palaeoregolith deposits as recorders of the galactic environment of the Solar System and implications for astrobiology. Earth Moon Planets 107:75-85.

Crites, S.T., Lucey, P.G., and Lawrence, D.J. (2013) Proton flux and radiation dose from galactic cosmic rays in the lunar regolith and implications for organic synthesis at the poles of the Moon and Mercury. Icarus 226:1192-1200.

Dartnell, L.R. (2011) Ionizing radiation and life. Astrobiology 11:551-582.

Demiral, İ. and Şensöz, S. (2008) The effects of different catalysts on the pyrolysis of industrial wastes (olive and hazelnut bagasse). Bioresour Technol 99:8002-8007.

Ehrenfreund, P. and Charnley, S.B. (2000) Organic molecules in the interstellar medium, comets, and meteorites: a voyage from dark clouds to the early Earth. Anпu Rev Astron Astrophys 38:427-483.

Elsila, J.E., Glavin, D.P., and Dworkin, J.P. (2009) Cometary glycine detected in samples returned by Stardust. Meteorit Planet Sci 44:1323-1330.

Espitalié, J., Madec, M., and Tissot, B. (1980) Role of mineral matrix in kerogen pyrolysis - influence on petroleum generation and migration. Am Assoc Pet Geol Bull 64:59-66.

Espitalié, J., Senga Makadi, K., and Trichet, J. (1984) Role of the mineral matrix during kerogen pyrolysis. Org Geochem $6: 365-382$.

Fagents, S.A. and Greeley, R. (2001) Factors influencing lavasubstrate heat transfer and implications for thermomechanical erosion. Bulletin of Volcanology 62:519-532.

Fagents, S.A., Rumpf, M.E., Crawford, I.A., and Joy, K.H. (2010) Preservation potential of implanted solar wind volatiles 
in lunar paleoregolith deposits buried by lava flows. Icarus 207:595-604.

Farrimond, P., Bevan, J.C., and Bishop, A.N. (1996) Hopanoid hydrocarbon maturation by an igneous intrusion. Org Geochem 25:149-164.

Fedo, C.M. and Whitehouse, M.J. (2002) Metasomatic origin of quartz-pyroxene rock, Akilia, Greenland, and implications for Earth's earliest life. Science 296:1448-1452.

Garvie, L.A.J. and Buseck, P.R. (2007) Prebiotic carbon in clays from Orgueil and Ivuna (CI), and Tagish Lake (C2 ungrouped) meteorites. Meteorit Planet Sci 42:2111-2117.

Gomes, R., Levison, H.F., Tsiganis, K., and Morbidelli, A. (2005) Origin of the cataclysmic Late Heavy Bombardment period of the terrestrial planets. Nature 435:466-469.

Gutiérrez, J.L. (2002) Terrene meteorites in the Moon: its relevance for the study of the origin of life in the Earth. In Proceedings of the First European Workshop on ExoAstrobiology, European Space Agency Special Publication, edited by H. Lacoste, ESA SP-518, Noordwijk, the Netherlands, pp 187-191.

Hartmann, W.K., Ryder, G., Dones, L., and Grinspoon, D. (2000) The time dependent intense bombardment of the primordial Earth/Moon system. In Origin of the Earth and Moon, edited by K. Righter and R. Canup, University of Arizona Press, Tucson, AZ, pp 493-512.

Haskin, L. and Warren, P. (1991) Lunar chemistry. In The Lunar Sourcebook: A User's Guide to the Moon, edited by G.H. Heiken, D. Vaniman, and B.M. French, Cambridge University Press, Cambridge, UK, pp 357-474.

Hauri, E.H., Weinreich, T., Saal, A.E., Rutherford, M.C., and Van Orman, J.A. (2011) High pre-eruptive water contents preserved in lunar melt inclusions. Science 333:213215.

Huizinga, B.J., Tannenbaum, E., and Kaplan, I.R. (1987) The role of minerals in the thermal alteration of organic matterIII. Generation of bitumen in laboratory experiments. Org Geochem 11:591-604.

Iñiguez, E., Navarro-González, R., de la Rosa, J., Ureña-Nuñez, F., Coll, P., Raulin, F., and McKay, C.P. (2009) On the oxidation ability of the NASA Mars-1 soil simulant during the thermal volatilization step: implications for the search of organics on Mars. Geophys Res Lett 36, doi:10.1029/ 2009GL040454.

Joy, K.H., Zolensky, M.E., Nagashima, K., Huss, G.R., Ross, D.K., McKay, D.S., and Kring, D.A. (2012) Direct detection of projectile relics from the end of the lunar basin-forming epoch. Science 336:1426-1429.

Joy, K.H., Crawford, I.A., Huss, G.R., Nagashima, K., and Taylor, G.J. (2014) An unusual clast in lunar meteorite MacAlpine Hills 88105: a unique lunar sample or projectile debris? Meteorit Planet Sci 49:677-695.

Kebukawa, Y., Nakashima, S., Ishikawa, M., Aizawa, K., Inoue, T., Nakamura-Messenger, K., and Zolensky, M.E. (2010) Spatial distribution of organic matter in the Bells CM2 chondrite using near-field infrared microspectroscopy. $\mathrm{Me}$ teorit Planet Sci 45:394-405.

Keller, L.P. and McKay, D.S. (1997) The nature and origin of rims on lunar soil grains. Geochim Cosmochim Acta 61: 2331-2341.

Kerr, R.C. (2001) Thermal erosion by laminar lava flows. J Geophys Res Solid Earth 106:26453-26465.

Killops, S. and Killops, V. (2005) Introduction to Organic Geochemistry, $2^{\text {nd }}$ ed., Blackwell Publishing, Malden, MA, pp 117-165.
Kissel, J. and Krueger, F.R. (1987) The organic component in dust from comet Halley as measured by the PUMA mass spectrometer on board Vega 1. Nature 326: 755-760.

Kminek, G. and Bada, J.L. (2006) The effect of ionizing radiation on the preservation of amino acids on Mars. Earth Planet Sci Lett 245:1-5.

Kring, D.A. and Cohen, B.A. (2002) Cataclysmic bombardment throughout the inner Solar System 3.9-4.0 Ga. J Geophys Res Planets 107, doi:10.1029/2001JE001529.

Le Guillou, C., Bernard, S., Brearley, A.J., and Remusat, L. (2014) Evolution of organic matter in Orgueil, Murchison and Renazzo during parent body aqueous alteration: in situ investigations. Geochim Cosmochim Acta 131:368-392.

Lepland, A., van Zuilen, M.A., Arrhenius, G., Whitehouse, M.J., and Fedo, C.M. (2005) Questioning the evidence for Earth's earliest life-Akilia revisited. Geology 33: 77-79.

Lewan, M.D. and Buchardt, B. (1989) Irradiation of organic matter by uranium decay in the Alum Shale, Sweden. Geochim Cosmochim Acta 53:1307-1322.

Lucey, P., Korotev, R.L., Gillis, J.J., Taylor, L.A., Lawrence, D., Campbell, B.A., Elphic, R., Feldman, B., Hood, L.L., Hunten, D., Mendillo, M., Noble, S., Papike, J.J., Reedy, R.C., Lawson, S., Prettyman, T., Gasnault, O., and Maurice, S. (2006) Understanding the lunar surface and space-moon interactions. Reviews in Mineralogy and Geochemistry 60: 83-219.

Lucey, P.G. (2000) Potential for prebiotic chemistry at the poles of the Moon. Proc SPIE 4137, doi:10.1117/12.411612.

Marchi, S., Bottke, W.F., Kring, D.A., and Morbidelli, A. (2012) The onset of the lunar cataclysm as recorded in its ancient crater populations. Earth Planet Sci Lett 325-326: 27-38.

Marchi, S., Bottke, W.F., Elkins-Tanton, L.T., Bierhaus, M., Wuennemann, K., Morbidelli, A., and Kring, D.A. (2014) Widespread mixing and burial of Earth's Hadean crust by asteroid impacts. Nature 511:578-582.

Marques, R., Prudêncio, M.I., Waerenborgh, J.C., Rocha, F., Dias, M.I., Ruiz, F., Ferreira da Silva, E., Abad, M., and Muñoz, A.M. (2014) Origin of reddening in a paleosol buried by lava flows in Fogo island (Cape Verde). J Afr Earth Sci 96:60-70.

McKay, D.S., Heiken, G.H., Basu, A., Blanford, G., Simon, S., Reedy, R., French, B.M., and Papike, J. (1991) The lunar regolith. In The Lunar Sourcebook: A User's Guide to the Moon, edited by G.H. Heiken, D. Vaniman, and B.M. French, Cambridge University Press, Cambridge, UK, pp 285-356.

McKay, D.S., Carter, J.L., Boles, W.W., Allen, C.C., and Allton, J.H. (1994) JSC-1: a new lunar soil simulant. In Engineering, Construction, and Operations in Space IV: Proceedings of Space 94, edited by R.G. Galloway and S. Lokaj, American Society of Civil Engineers, New York, pp 857-866.

McSween, H.Y., Jr. (1976) A new type of chondritic meteorite found in lunar soil. Earth Planet Sci Lett 31:193-199.

Mojzsis, S.J., Arrhenius, G., McKeegan, K.D., Harrison, T.M., Nutman, A.P., and Friend, C.R.L. (1996) Evidence for life on Earth before 3,800 million years ago. Nature 384: 55-59.

Moore, M.H., Donn, B., Khanna, R., and A'Hearn, M.F. (1983) Studies of proton-irradiated cometary-type ice mixtures. Icarus 54:388-405. 
Morbidelli, A., Marchi, S., Bottke, W.F., and Kring, D.A. (2012) A sawtooth-like timeline for the first billion years of lunar bombardment. Earth Planet Sci Lett 355-356:144151.

Nagy, B., Drew, C.M., Hamilton, P.B., Modzeleski, V.E., Murphy, S.M.E., Scott, W.M., Urey, H.C., and Young, M. (1970) Organic compounds in lunar samples: pyrolysis products, hydrocarbons, amino acids. Science 167:770-773.

Olson, C.G. and Nettleton, W.D. (1998) Paleosols and the effects of alteration. Quat Int 51-52:185-194.

Papike, J.J., Simon, S.B., and Laul, J.C. (1982) The lunar regolith-chemistry, mineralogy, and petrology. Rev Geophys 20:761-826.

Parnell, J., Bowden, S., Lindgren, P., Burchell, M., Milner, D., Price, M., Baldwin, E.C., and Crawford, I.A. (2010) The preservation of fossil biomarkers during meteorite impact events: experimental evidence from biomarker-rich projectiles and target rocks. Meteorit Planet Sci 45:1340 1358.

Parnell, J., Bowden, S.A., Muirhead, D., Blamey, N., Westall, F., Demets, R., Verchovsky, S., Brandstätter, F., and Brack, A. (2011) Preservation of organic matter in the STONE 6 artificial meteorite experiment. Icarus 212:390-402.

Pearson, V.K., Sephton, M.A., Kearsley, A.T., Bland, P.A., Franchi, I.A., and Gilmour, I. (2002) Clay mineral-organic matter relationships in the early Solar System. Meteorit Planet Sci 37:1829-1833.

Persenaire, O., Alexandre, M., Degee, P., and Dubois, P. (2001) Mechanisms and kinetics of thermal degradation of poly $(\varepsilon-$ caprolactone). Biomacromolecules 2:288-294.

Pierazzo, E. and Chyba, C.F. (1999) Amino acid survival in large cometary impacts. Meteorit Planet Sci 34:909-918.

Pieters, C.M., Goswami, J.N., Clark, R.N., Annadurai, M., Boardman, J., Buratti, B., Combe, J.-P., Dyar, M.D., Green, R., Head, J.W., Hibbitts, C., Hicks, M., Isaacson, P., Klima, R., Kramer, G., Kumar, S., Livo, E., Lundeen, S., Malaret, E., McCord, T., Mustard, J., Nettles, J., Petro, N., Runyon, C., Staid, M., Sunshine, J., Taylor, L.A., Tompkins, S., and Varanasi, P. (2009) Character and spatial distribution of $\mathrm{OH} /$ $\mathrm{H}_{2} \mathrm{O}$ on the surface of the Moon seen by M3 on Chandrayaan1. Science 326:568-572.

Pillinger, C.T. and Eglinton, G. (1977) The chemistry of carbon in the lunar regolith. Philos Trans R Soc Lond A 285:369377.

Ponnamperuma, C., Kvenvolden, K., Chang, S., Johnson, R., Pollock, G., Philpott, D., Kaplan, I., Smith, J., Schopf, J.W., Gehrke, C., Hodgson, G., Breger, I.A., Halpern, B., Duffield, A., Krauskopf, K., Barghoorn, E., Holland, H., and Keil, K. (1970) Search for organic compounds in the lunar dust from the Sea of Tranquility. Science 167:760-762.

Quirico, E., Raynal, P.I., and Bourot-Denise, M. (2003) Metamorphic grade of organic matter in six unequilibrated ordinary chondrites. Meteorit Planet Sci 38:795-811.

Rapagnà, S., Jand, N., Kiennemann, A., and Foscolo, P.U. (2000) Steam-gasification of biomass in a fluidised-bed of olivine particles. Biomass Bioenergy 19:187-197.

Robinson, K.L. and Taylor, G.J. (2014) Heterogeneous distribution of water in the Moon. Nat Geosci 7:401-408.

Rumpf, M.E., Fagents, S.A., Crawford, I.A., and Joy, K.H. (2013) Numerical modeling of lava-regolith heat transfer on the Moon and implications for the preservation of implanted volatiles. J Geophys Res Planets 118:382-397.

Saal, A.E., Hauri, E.H., Cascio, M.L., Van Orman, J.A., Rutherford, M.C., and Cooper, R.F. (2008) Volatile content of lunar volcanic glasses and the presence of water in the Moon's interior. Nature 454:192-195.

Saal, A.E., Hauri, E.H., Van Orman, J.A., and Rutherford, M.J. (2013) Hydrogen isotopes in lunar volcanic glasses and melt inclusions reveal a carbonaceous chondrite heritage. Science 340:1317-1320.

Sagan, C. (1960) Indigenous organic matter on the Moon. Proc Natl Acad Sci USA 46:393-396.

Sandford, S.A., Aléon, J., Alexander, C.M.O.D., Araki, T., Bajt, S., Baratta, G.A., Borg, J., Bradley, J.P., Brownlee, D.E., Brucato, J.R., Burchell, M.J., Busemann, H., Butterworth, A., Clemett, S.J., Cody, G., Colangeli, L., Cooper, G., D'Hendecourt, L., Djouadi, Z., Dworkin, J.P., Ferrini, G., Fleckenstein, H., Flynn, G.J., Franchi, I.A., Fries, M., Gilles, M.K., Glavin, D.P., Gounelle, M., Grossemy, F., Jacobsen, C., Keller, L.P., Kilcoyne, A.L.D., Leitner, J., Matrajt, G., Meibom, A., Mennella, V., Mostefaoui, S., Nittler, L.R., Palumbo, M.E., Papanastassiou, D.A., Robert, F., Rotundi, A., Snead, C.J., Spencer, M.K., Stadermann, F.J., Steele, A., Stephan, T., Tsou, P., Tyliszczak, T., Westphal, A.J., Wirick, S., Wopenka, B., Yabuta, H., Zare, R.N., and Zolensky, M.E. (2006) Organics captured from comet 81P/Wild 2 by the Stardust spacecraft. Science 314:1720-1724.

Sears, D.W. (1975) Temperature gradients in meteorites produced by heating during atmospheric passage. Modern Geology 5:155-164.

Sephton, M.A. (2002) Organic compounds in carbonaceous meteorites. Nat Prod Rep 19:292-311.

Sephton, M.A., Verchovsky, A.B., and Wright, I.P. (2004a) Carbon and nitrogen isotope ratios in meteoritic organic matter: indicators of alteration processes on the parent asteroid. International Journal of Astrobiology 3:221-227.

Sephton, M.A., Bland, P.A., Pillinger, C.T., and Gilmour, I. (2004b) The preservation state of organic matter in meteorites from Antarctica. Meteorit Planet Sci 39:747-754.

Sheldon, N.D. (2003) Pedogenesis and geochemical alteration of the Picture Gorge subgroup, Columbia River basalt, Oregon. Geol Soc Am Bull 115:1377-1387.

Steele, A., McCubbin, F.M., Fries, M., Glamoclija, M., Kater, L., and Nekvasil, H. (2010) Graphite in an Apollo 17 impact melt breccia. Science 329:51.

Taylor, L.A., Pieters, C.M., Keller, L.P., Morris, R.V., and McKay, D.S. (2001) Lunar mare soils: space weathering and the major effects of surface-correlated nanophase Fe. $J$ Geophys Res Planets 106:27985-27999.

Thomas, K.L., Keller, L.P., Blanford, G.E., and McKay, D.S. (1994) Quantitative analyses of carbon in anhydrous and hydrated interplanetary dust particles. In Analysis of Interplanetary Dust: NASA/LPI Workshop, Houston, TX May 1993, edited by M.E. Zolensky, T.L. Wilson, F.J.M. Rietmeijer, and G.J. Flynn, AIP Conference Proceedings 310, American Institute of Physics, New York, pp 165-172.

Thomas-Keprta, K.L., Clemett, S.J., Messenger, S., Ross, D.K., Le, L., Rahman, Z., McKay, D.S., Gibson, E.K., Jr., Gonzalez, C., and Peabody, W. (2014) Organic matter on the Earth's moon. Geochim Cosmochim Acta 134:1-15.

Tian, M., Liu, B.S., Hammonds, M., Wang, N., Sarre, P.J., and Cheung, A.S.-C. (2013) Catalytic conversion of acetylene to polycyclic aromatic hydrocarbons over particles of pyroxene and alumina. Philos Trans A Math Phys Eng Sci 371, doi: 10.1098/rsta.2011.0590.

Tsiganis, K., Gomes, R., Morbidelli, A., and Levison, H.F. (2005) Origin of the orbital architecture of the giant planets of the Solar System. Nature 435:459-461. 
van Kranendonk, M.J., Smithies, H.R.H., and Bennett, V., editors. (2007) Earth's Oldest Rocks, Developments in Precambrian Geology Vol. 15, Elsevier, Amsterdam.

Vaniman, D.T., Reedy, R., Heiken, G.H., Olhoeft, G., and Mendell, W.W. (1991) The lunar environment. In The Lunar Sourcebook: A User's Guide to the Moon, edited by G.H. Heiken, D.T. Vaniman, and B.M. French, Cambridge University Press, Cambridge, UK, pp 27-60.

Wilhelms, D.E., McCauley, J.F., and Trask, N.J. (1987) The Geologic History of the Moon, US Geological Survey Professional Paper 1348, United States Geological Survey, Department of the Interior, Washington, DC.

Willman, B.M., Boles, W.W., McKay, D.S., and Allen, C.C. (1995) Properties of lunar soil simulant JSC-1. J Aerosp Eng 8:77-87.

Zega, T.J., Alexander, C.M.O.D., Busemann, H., Nittler, L.R., Hoppe, P., Stroud, R.M., and Young, A.F. (2010) Mineral associations and character of isotopically anomalous organic material in the Tagish Lake carbonaceous chondrite. Geochim Cosmochim Acta 74:5966-5983.

Zolensky, M.E. (1997) Structural water in the Bench Crater chondrite returned from the Moon. Meteorit Planet Sci 32:15-18.

Zolensky, M.E., Weisberg, M.K., Buchanan, P.C., and Mittlefehldt, D.W. (1996) Mineralogy of carbonaceous chondrite clasts in HED achondrites and the Moon. Meteorit Planet Sci 31:518-537.
Address correspondence to: Richard Matthewman

Department of Earth Science and Engineering South Kensington Campus Imperial College London London SW7 $2 A Z$

$U K$

E-mail: r.matthewman@imperial.ac.uk

Submitted 29 August 2014

Accepted 6 December 2014

\begin{tabular}{|c|}
\hline Abbreviations Used \\
GC-MS $=$ gas chromatography-mass \\
spectrometry \\
JSC-1 $=\begin{array}{l}\text { lunar regolith analogue Johnson } \\
\text { Space Center } 1\end{array}$ \\
$\mathrm{MSD}=$ mass selective detector \\
$\mathrm{PAH}=$ polycyclic aromatic hydrocarbon \\
$\mathrm{PCL}=$ poly $(\varepsilon-$-caprolactone $)$ \\
$\mathrm{PHB}=$ poly $[(\mathrm{R})-3$-hydroxybutyrate $]$ \\
pyrolysis-GC-MS $=$ pyrolysis-gas chromatography- \\
mass spectrometry
\end{tabular}

